\title{
The Prevalence, Risk Factors and Treatment Methods for Tungiasis among Residents of Musokoto Sub-Location, in Kenya
}

\author{
Article by Ngetich Albert ${ }^{1}$, Kirorei Kiprotich ${ }^{2}$ \\ Ph.D. in Public Health, Texila American University, Kenya \\ E-mail: ngetichalbert@yahoo.com
}

\begin{abstract}
Tungiasis is a parasitic skin disease caused by sand flea Tunga penetrans. In Kenya, little data has been published regarding tungiasis. In Nambale health centre, tungiasis accounted for $4 \%$ of total morbidities. Therefore this study sought to assess the prevalence of, risk factors and treatment methods for tungiasis among residents of Musokoto, in Kenya. Purposive sampling method was used. Logistic regression was used to determine the risks factors associated with tungiasis. A total 1557 participant from 333 randomly selected households took part in the study. Of the 1557 participants, a total of 441(28.3\%) at least had jiggers at one point in their life. Out of the 441, 287(65\%) were confirmed to have jiggers on examination whereas $9(2 \%)$ did not have jigger by the time of the study. Toes on the extreme sites were more infested however the distribution of infestation was moral less the same for the all toes. Above 50\% of those infested were aged 10 years and below. Logistical regression analysis revealed that place of sleeping $(P<0.001, \mathrm{OR}=1.319, \mathrm{CI}=1.180-1.474)$ significantly influenced jiggers infestation. The type of floor of the house $(P=0.036, O R=$ 3.608, CI $=1.089$ - 11.955) was also found to significantly influence jiggers infestation. Source of water was more likely to influence jigger infestation $(P=0.001, O R=2.050, C I=$ 1.334 - 3.150). The results are essential for community, local Public Health Officers, national and international public health agencies for interventions aimed at controlling jigger's infestation.
\end{abstract}

Keywords: Tunga penetran, Tungiasis, Ectoparasitosis and Fecundation.

\section{Introduction}

Tungiasis is a parasitic skin disease caused by female sand flea Tunga penetran, which burrows into the skin usually, on the feet (Collins et al., 2009). It is also a neglected public health problem in endemic areas in Latin America, the Caribbean and Africa, and causes considerable morbidity in the affected communities. Ugbomoiko et al., 2007 stated that, despite its notoriety tungiasis is not regarded a serious health problem of which this is a misconception.

This flea lives in the soil or sand and feeds intermittently on hosts such as humans, domestic animals such as cattle, sheep, pigs, chickens, dogs, mice and wild animals. The preferred habitats of Tunga penetrans are warm, dry environments with sandy soil and dust (Sanusi et al., 1989; Winter et al., 2009). They enter human hosts through penetration in the skin. The ectoparasitosis is associated with poverty and occurs in many resource-poor communities in the Caribbean, South America and Africa and these communities prevalence may be as high as $50 \%$ in the general population. (Feldmeier et al., 2004).

Tunga penetrans is known to cause significant debilitation in areas of deprived resources and infrastructure. The jigger flea is the smallest known flea, measuring less than $1 \mathrm{~mm}$ in length (Feldmeier et al., 2004). After entering its host (both humans and domesticated animals), the gravid female flea undergoes substantial growth, growing to around 2000 times its size (640 um) in six days.

The sand flea became known to the Spaniards not long after Christopher Columbus had landed at the American continent in 1492 and was probably inadvertently introduced into Angola in the $17^{\text {th }}$ till $19^{\text {th }}$ century by ship, subsequently spreading all over Africa, Pakistan 
and West India along the trade routes and by expeditions (Heemskerk et al., 2005). Although endemic in tropical America, Africa and West India, knowledge of this infection is rare in Europe and Northern America. The sand flea originally occurred only on the American continent and the Caribbean Islands, but spread in the late $19^{\text {th }}$ century throughout subSaharan Africa and to Madagascar (Hoeppli, 1963); (Heukelbach, 2004)). Two recent studies from Nigeria and Cameroon indicate that still today tungiasis is a major public health problem in West Africa (Njeumi et al., 2002). A study conducted in Northwest Cameroon by Collin et al., 2009) showed that out of 1,151 individuals that were examined, 610 individuals (53\%) were infested with Tunga penetrans with the prevalence highest in children, diminishing in adults and then increasing again in the elderly.

Ahadi Kenya Trust, an organization that works in Kenya to eradicate the jigger flea, estimates that the jigger flea may infect over 2.6 million Kenyans. Many people have been suffering from jigger infestation in silence. No comprehensive survey has been carried out, making it difficult to give actual number of those affected (Ahadi Trust, 2010).

Studies done in Muranga and Uasin Gishu by Njau et al., (2012) and Choge et al., (2006) respectively showed that prevalence in those districts among children 5-14 years was 67\% and 21\% respectively. Further interventional studies carried out in neighboring Emuhaya constituency revealed that 39\% of Ematsuli primary school had tungiasis. Majority of the children walked barefooted to school increasing the risk of infestation (BDSP, 2010). Prevalence in the hospital was reported to be $4 \%$ of the total morbidities. However, the prevalence of tungiasis is uncertain in the entire Musokoto community and other adjacent locations. Therefore the study sought to establish the prevalence of Tungiasis in the location.

Despite its notoriety, the jigger flea is not regarded as a serious threat to health (Ugbomoiko et al., 2007). Unfortunately this is a common misconception. Tungiasis results in significant morbidity, manifesting itself in a number of symptoms such as severe local inflammation, auto-amputation of digits, deformation and loss of nails, formation of fissures and ulcers, gangrene and walking difficulties. Secondary infection also poses considerable risk; many lacking immunisation are vulnerable to tetanus (Clostridium tetani), often proving fatal. Complaints of insomnia are also common due to the intolerable itchiness of the infestation (Muehlen et al., 2006).

Muenhlen et al., (2006) states that the common factors that are seen to aggravate tungiasis include poor housing conditions, lack of water, poor hygiene and wearing open shoes. He further revealed that viable prevention and intervention methods for combating the disease include paving of public areas and house floors and the use of closed shoes when feet touch contaminated soil. While shoes could serve well in reducing invasion of the Tunga penetrans, the problem here lies in affordability. Given that where tungiasis prevails the population is poor, shoes may not be seen as a priority. A probable intervention could be regular inspection of feet and immediate extraction of embedded fleas with subsequent disinfection of the lesion to protect against infections (Wachira, 2012).

In the past few years, the public health importance of tungiasis in resource-poor populations has been highlighted from different countries, including Brazil, Argentina, Haiti and Nigeria (Joseph et al., 2006). Pilger et al. (2008) argues that tungiasis is much more prevalent in communities who usually wear flip - flop (slippers) and often sleep on dirty floors. The challenges with the term dirty floor that Pilger and colleagues, (2008) did not clarify the meaning of dirty floors. However, risk factors for infestation have only been addressed in a single study from Brazil (Muehlen et al., 2006) nevertheless sustainable intervention measures have never been assessed systematically. In Kenya, a study done in Muranga by Njau et al., (2012) concluded that the risk factors for tungiasis in the area were walking barefoot, keeping domesticated animals especially pigs and dogs and living in mad build houses. No risk factor studies have been conducted in the neighboring location of Musokoto.

Ahadi Trust (2010) outlines the treatment of tungiasis through washing of affected areas with soap and water, dry the cleaned areas, soaking the affected areas with potassium 
permanganate or disinfect with savlon solution for 15 minutes, then application of petroleum jelly to the affected area. A clinical trial study by Heukelbach, (2002) shows that ivermectin 200mg tablets are effective in treatment of tungiasis for a period of two weeks. However, due to the zoonotic aspect of Tungiasis, control of affected communities is much more complicated and challenging than in other ectoparasites associated with poverty, such as scabies and pediculosis, which do not have animal hosts (Heukelbach et al., 2004). Domesticated animals such as dogs, cats, pigs and goats should be treated with available onanimal insecticides, including collars, shampoos and sprays. In addition, environmental insecticides could be used during the early and late stages of the flea to break the life cycle. With the challenge of having virtually non-existent epidemiologic data on tungiasis, control measures can only be planned when the weight of the disease, underlying forces behind the spread and risk factors are better understood (Ugbomoiko, 2007).

At Musokoto most residents have built temporary structures for housing with roofs made of either tin/metal and/or thatched. Floors and walls are smeared with mad or clay, which could be associated with tungiasis infestation. Treatment of tungiasis at Nambale health center is an ongoing process and accounts for $4 \%$ of the total morbidities. The majority of the cases are children and the elderly. The prevalence of tungiasis cases in the outpatient department of Nambale health center serving Musokoto residents is known but the prevalence in the entire community is not yet established. Lack of knowledge on the overall prevalence of tungiasis in Musokoto could deter the government and other stakeholders to put in place interventions that could help in controlling and prevent further cases of tungiasis. Treatment methods and products used by the residents of Musokoto sub-location is still not known. Knowing the treatment methods used by residents of musokoto is critical in as so much that this would highlight whether or not the residents are using effective methods that eventually would put under control tungiasis infestation. Lack of knowledge on the risk factors associated with tungiasis impedes advice measures that could be given to residents of musokoto to enable community led interventions in controlling tungiasis by taking care of such risk factors. Hence this study aims at identifying prevalence of tungiasis infestation, risk factors associated with tungiasis and modes of treatment used by Musokoto residents to treat tungiasis cases.

Epidermal parasitic skin diseases (EPSD) occur worldwide and have been known since ancient times. Despite the considerable burden caused by EPSD, this category of parasitic diseases has been widely neglected by the scientific community and health-care providers (WHO, 2010). Tungiasis has many clinical features of a neglected tropical disease and thus can be considered as a paradigm: it is endemic in poor communities and rural areas, it is associated with stigma, and there are no products in the commercial markets targeting the treatment of the disease (Heukelbach et al., 2001; Molyneux et al., 2005). Despite the fact that the prevalence of tungiasis in Musokoto is $4 \%$ according to the hospital data (BDSP, 2010), the actual prevalence of tungiasis in the entire community of musokoto is not known and so it is important that a study of this nature was carried out to establish the actual prevalence of tungiasis in the entire population.

Tungiasis is a manageable parasitic infestation and the use of proper treatment methods should put tungiasis under control. Nevertheless, the treatment methods used by residents of Musokoto to control tungiasis are uncertain and so it was imperative that an investigation of this nature carried out to establish the treatment methods used by these residents. Sustainability of treatment outcomes depends on several factors including but not limited to household risk factors that could favor persistent tungiasis infestation of Musokoto residents. Knowing of such risk factors would assist in devising appropriate interventions to control tungiasis. It was thus necessary to investigate the risk factors associated with tungiasis infestation among residents of Musokoto sub location. 
Texila International Journal of Public Health

Volume 4, Issue 4, Dec 2016

\section{Methodology}

\section{Study site}

Musokoto sub-location is a region in western Kenya $30 \mathrm{~km}$ to the Busia border between Kenya and Uganda. Its coordinates are $0^{\circ} 26^{\prime} \mathrm{N} 34^{\circ} 9^{\prime} \mathrm{E}$. It borders three sub-locations namely Bukhayo central, Kwilare and Bukhayo East. (BDSP, 2010). The Musokoto sub-location and its villages are governed by assistant chief and village elders respectively. Majority of the population has lived in the area since birth except for migrants working in various organizations/institutions in the little town of Nambale.

The community can be regarded as a typical rural settlement. Majority of the residents live in temporary houses of thatched houses with mud smeared walls and floor. Different weather patterns of dry seasons and rainy seasons occur i.e. January - March dry season and April august are rainy seasons. Economically they depend on agriculture for a living as major source of income through cattle keeping, fishing and farming (majorly maize and beans). Domestic animals (pigs, goats, sheep and dogs) roam around in the villages. There is poor infrastructure of road networks as roads in the division are not tarmac (BDSP, 2010).

The community lacks appropriate urban services like electricity, pipe-borne water and a public sewage system. Open wells, boreholes and the nearby rivers serve as the source of water. It is served by only one major health facility other being dispensaries in other sublocations. The majority of the people walk barefooted, defecates in the surrounding bush and scatter domestic waste in the vicinity of their homes as observed (BDSP, 2010). Its position is as shown in appendix G: study site map.

\section{Study population}

The total population of Musokoto sub-location is 3,335 persons and with 667 households. It is composed of eight villages namely Kaludeka, katomei, logiri, Walatsi, Makutano, Otiri, Musoma and Ongaroi. The Public health officers in the area estimated that the sub-location had frequent cases of tungiasis as reported from the school going children. Nambale division, where Musokoto location is based has poverty levels stand at 64.5 percent hence a high risk factor for tungiasis (BDSP, 2010).

\section{Study design}

A cross sectional study design using mixed data collection method i.e. semi-structured questionnaire for quantitative data and key informant interviews for qualitative data was adopted. Cross sectional design involves observation of all of a population, or a representative subset, at one specific point in time (Groove, 2003).

\section{Sample size determination}

To get the representative sample for the household's population a sample size estimation formula of Yamane was use (Yamane, 1967).

\section{Sampling procedure}

Purposive sampling method was used to select Musokoto sub-location based on the previous reports of tungiasis prevalence from the health center. This is because most treated cases of tungiasis at Nambale health center originated from Musokoto sub-location. The 8 villages in the sub location were used in the study and 333 households were sampled using proportionate systematically random sampling at a sampling interval of 2 .

\section{Data collection}

Before the onset of the study information meetings was held with the community administrative leaders such as chiefs, sub-chief and the village elders at their respective territories. Selection and recruitment of a nurse and 8 community health workers (from respective village) was done. The nurse recruited aided in supervision and collection of data. Community health workers were given codes and identification cards. Training and a pilot 
study was carried out in two of the villages in Kwilare sub-location in the division and 20 households picked at random for piloting. Details shown in table 3.2 below. Validity and reliability was accepted at a reliability co-efficient of 0.70 .

\section{Data collection tools}

Quantitative data collection methods were adopted for the study. During the study, randomly sampled households were visited and members examined for the presence of embedded sand fleas. The pre-tested questionnaire was then applied in English.

\section{Measurement of variables}

The information collected consisted of five categories: (1) socio-demographic factors (such as sex, age, education); (2) housing and associated factors (such as type of construction of the house, type of floor inside house, sanitary conditions, presence of electricity, waste disposal); (3) ownership and presence of domestic animals; (4) clinical and personal effects brought about by Tunga penetrans infestation (5) knowledge, attitudes and practices related to tungiasis (such as knowledge on transmission, regular use of footwear, common resting place, preventive measures, treatment). Children of 6 years and above to provide information directly, while in the other cases information will be obtained from the guardians after their consent. Legal guardians/parents will sign their consents forms. A household was revisited when a family member was absent.

Clinical examination performed by inspecting carefully the legs, feet, hands and arms. To guarantee privacy, other topographical regions of the body not examined. This approach is considered acceptable, as in endemic communities more than $99 \%$ of tungiasis lesions occur on legs, feet, hands and arms (Heukelbach et al., 2002).

During clinical examinations the following findings was considered diagnostic for tungiasis: an itching red-brownish spot with a diameter of 1-3 mm, a circular lesion presenting as a white patch with a diameter of 1-4 mm with a central black dot, black crust surrounded by necrotic tissue, as well as partially or totally removed fleas leaving a characteristic sore in the skin (Eisele et al., 2003). Localization and number of lesions recorded. As defined by Muehlen et al., 2006 the presence of less than 5 lesions considered as mild, of 6-30 as moderate and of more than 30 lesions as heavy infestation. All clinical examinations and interviews was done by a single person, to eliminate inter-observer bias. If a household member is found positive of tungiasis, Servin Dudu dust applied in the living area.

\section{Statistical analysis}

Data was entered using Epi Info software (version 6.04; Centers for Disease Control and Prevention, Atlanta, USA) and checked for entry errors by rechecking all data entries with the original data forms. Then, data was transferred to IBM Statistical package software (version 17.0) for analysis.

Prevalence was determined as percentage of infested individual out of total household population examined for tungiasis. Logistic regression was used to establish the risk factors that affected the jiggers infestation. Bivariate analysis was also carried out to calculate how different combined variables could affect the risks factors.

\section{Ethical considerations}

Permission to perform the study was obtained from Maseno University Graduate studies (SGS) and authorization sought from Maseno university ethics committee. Participation was voluntary after counseling using a participants counseling form and consent by participants was on the basis of participation. Potential risks and benefits were explained in the form.

Confidentiality of the participants assured prior to filling of the questionnaires and all data collected was not shared and stored by only the investigator in his private computer. The 
Texila International Journal of Public Health

Volume 4, Issue 4, Dec 2016

participants explained to about the purpose of the study, its duration and benefits of the research stud and they were given an opportunity to ask questions where need arises.

\section{Results}

\section{Socio-demographic and economic profile of the household members}

\section{Socio-demographic characteristics of the study participants}

A total of 1557 participants randomly selected from 333 households took part in the study. Out of this study participants 768(49.3\%) were males whereas females were 789 (50.7\%). Almost half, 777(49.87\%) were aged 15 years and below, 652(41.87\%) were aged between 16-50 years old and only $128(8.2 \%)$ were more than 50 years old. About two thirds, 927(59.5\%) of the study participants were single; 247(15.9\%) were married with 144(9.2\%) and 239(15.4\%) being separated/divorced and widowed respectively. The details are contained in table 4.1 below.

Table 4.1. Socio-demographic characteristics of the study participants

\begin{tabular}{|c|c|c|}
\hline Variable & & Frequency n(\%) \\
\hline \multicolumn{3}{|l|}{ Gender } \\
\hline Male & & $768(49.3)$ \\
\hline Female & & 789(50.7) \\
\hline \multicolumn{3}{|c|}{ Age distribution (years) } \\
\hline $1-5$ & & $300(19.3)$ \\
\hline $6-10$ & & 285(18.3) \\
\hline $11-15$ & & \\
\hline $16-20$ & $175(11.2)$ & \\
\hline $21-25$ & $124(8.0)$ & \\
\hline $26-30$ & $132(8.5)$ & \\
\hline $31-35$ & $75(4.8)$ & \\
\hline $36-40$ & $76(4.9)$ & \\
\hline $45-50$ & $70(4.5)$ & \\
\hline$>50$ & & $128(8.2)$ \\
\hline \multicolumn{3}{|l|}{ Marital status } \\
\hline Single & & $927(59.5)$ \\
\hline Married & & 247(15.9) \\
\hline Separated/divorced & & $144(9.2)$ \\
\hline Widow & & 239(15.4) \\
\hline
\end{tabular}

\section{Socio-economic characteristics of the study participants}

The socio-economic parameters of the study participant that were investigated included level of education, main occupation and religion. Majority of the participants, 1369(87.9\%) had at least completed primary level of education 65(4.2\%) did not complete their primary education, 47(3.0\%) completed their secondary education with 27(1.7\%) not completing secondary education, only $10(0.6 \%)$ had at least tertiary/university education and lastly 40(2.6\%) were illiterate. Approximately a third, 477(30.6\%) of the study participants were students, 300(19.3\%) were considered as under-aged and so were not in any employment, 278(17.9\%) worked as house helps, 223(14.3\%) were farmers, 126(8.1\%) were housewives yet $121(7.8 \%)$, and $7(0.4 \%)$ were traders and civil servants respectively. A paltry 25(1.6\%) were not employed. On religion the study established that 1552(99.7\%) were Christians and only 5(0.5\%) were of the Muslim faith. Table 4.2 is on socio-economic characteristics of the study participants. 
Table 4.2. Socio-economic characteristics of the study participants

\begin{tabular}{lll}
\hline Variable & & Frequency n(\%) \\
\hline $\begin{array}{l}\text { Level of education } \\
\quad \text { Illiterate }\end{array}$ & & $40(2.6)$ \\
$\quad$ Primary complete & $1369(87.9)$ & \\
$\quad$ Primary incomplete & & $65(4.2)$ \\
$\quad$ Secondary complete & & $47(3.0)$ \\
Secondary incomplete & & $26(1.7)$ \\
Technical/university & & $10(0.6)$ \\
Main occupation & & \\
Under-age & $300(19.3)$ & \\
$\quad$ Farmer & $223(14.3)$ & \\
Trader/town & $121(7.8)$ & \\
House help & $278(17.9)$ & \\
House wife & $126(8.1)$ & \\
Civil servant & $7(0.4)$ & \\
Students & $477(30.6)$ & \\
No work & $25(1.6)$ & \\
Religion & & \\
Christian & $1552(99.7)$ & \\
Muslim & $5(0.3)$ & \\
\hline N = 1557. & & \\
\hline
\end{tabular}

\section{Prevalence of tungiasis among residents of Musokoto sub-location.}

Of the 1557 that participated in the study a total of $441(28.3 \%)$ said they at least had jiggers at one point in their life whereas 116(71.7\%) said they never had jiggers. Of the 441 who said they had jiggers, 287(65\%) of them had jiggers on examination whereas $9(2 \%)$ did not have jiggers found on them while $145(33 \%)$ refused to be examined by the nurse. See figure 4.1.

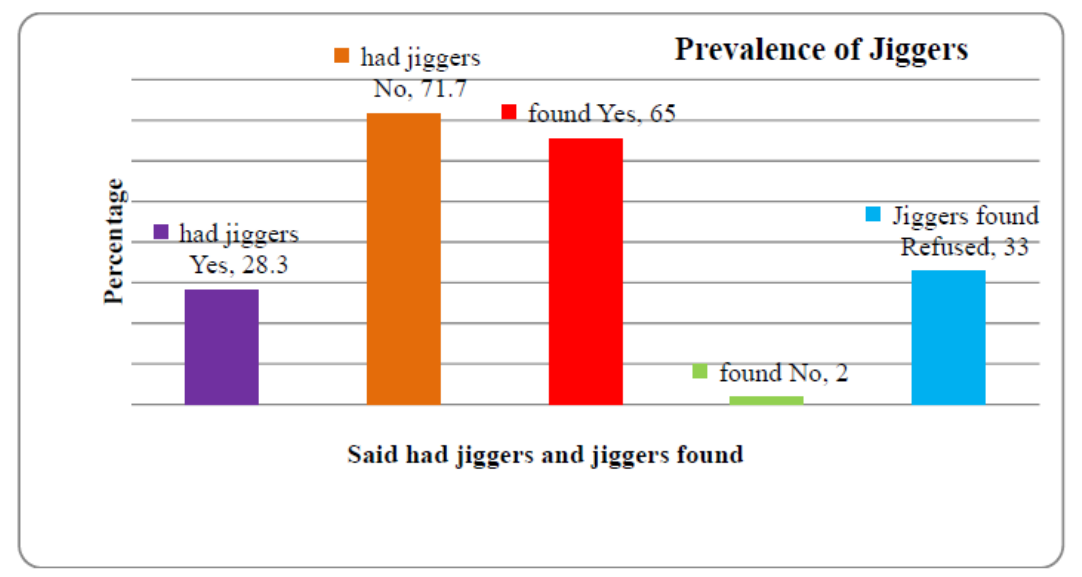

Figure 4.1. Percentage of participants who said they had jiggers and Jiggers were found on screening.

Prevalence of Tungiasis, socio-demographic and economic characteristics of the study participants

The jiggers infestation was significantly influenced by the household size $(\mathrm{P}=0.002$, $\mathrm{OR}=1.424$, $\mathrm{CI}=1.137-1.784)$, occupation $(\mathrm{P}<0.001$, $\mathrm{OR}=1.129$, $\mathrm{CI}=1.085-1.175)$ and education $(\mathrm{P}=0.025, \mathrm{OR}=1.187, \mathrm{CI}=1.021-1.379)$ of the participants. See table 4.3. 
Texila International Journal of Public Health

Volume 4, Issue 4, Dec 2016

Table 4.3. Association between jiggers infestation and socio-demographic and economic factors.

\begin{tabular}{|l|l|l|l|l|l|}
\hline Variable & Df & \multicolumn{1}{c|}{ Sig } & \multicolumn{1}{c|}{ OR } & \multicolumn{2}{c|}{ 95\% C.I } \\
\hline & & & & Lower & Upper \\
\hline Household size & 1 & 0.002 & 1.424 & 1.137 & 1.784 \\
\hline Gender & 1 & 0.738 & 0.963 & 0.772 & 1.201 \\
\hline Age & 1 & $<0.001$ & 0.888 & 0.852 & 0.926 \\
\hline Marital status & 1 & $<0.001$ & 0.749 & 0.672 & 0.837 \\
\hline Occupation & 1 & $<0.001$ & 1.129 & 1.085 & 1.175 \\
\hline Education & 1 & 0.025 & 1.187 & 1.021 & 1.379 \\
\hline
\end{tabular}

\section{Site infested and severity of the infestation}

On assessment on severity of tungiasis it emerged that toes on the extreme sites were more infested even though the distribution of infestation was more or less the same for all the toes. Severity reveals that the first toes were less severely infested as opposed to the fourth and fifth toes in regardless of site of infestation.

Table 4.4. Severity of infestations of the toes

\begin{tabular}{|l|l|l|l|l|}
\hline & \multicolumn{3}{|c|}{$\begin{array}{c}\text { Frequency n(\%) of severity of } \\
\text { infestation of toes }\end{array}$} \\
\hline Toe infested & \multicolumn{1}{|c|}{ Mild } & Moderate & \multicolumn{1}{|c|}{ Severe } & Total infested n(\%) \\
\hline & & & & \\
\hline $1^{\text {st }}$ Left toe & $91(46.2)$ & $74(37.6)$ & $32(16.2)$ & $197(12.80)$ \\
\hline $1^{\text {st }}$ Right toe & $48(52.2)$ & $44(47.8)$ & $0(0.0)$ & $92(5.97)$ \\
\hline $2^{\text {nd }}$ Left toe & $37(20.56)$ & $33(18.33)$ & $110(61.11)$ & $180(11.69)$ \\
\hline $2^{\text {nd }}$ Right toe & $31(20.7)$ & $30(20.0)$ & $89(59.3)$ & $150(9.74)$ \\
\hline $3^{\text {rd }}$ left toe & $20(21.7)$ & $32(34.8)$ & $40(43.5)$ & $92(5.98)$ \\
\hline $3^{\text {rd }}$ Right toe & $23(19.5)$ & $31(26.3)$ & $64(54.2)$ & $118(7.67)$ \\
\hline $4^{\text {th }}$ Left toe & $56(32.2)$ & $21(12.1)$ & $97(55.7)$ & $174(11.30)$ \\
\hline $4^{\text {th }}$ Right toe & $29(18.7)$ & $19(12.3)$ & $107(69.0)$ & $155(10.08)$ \\
\hline $5^{\text {th }}$ Left toe & $83(45.9)$ & $42(23.2)$ & $56(30.9)$ & $181(11.77)$ \\
\hline $5^{\text {th }}$ Right toe & $88(44.0)$ & $49(24.5)$ & $63(31.5)$ & $200(13.00)$ \\
\hline Totals & 506 & 378 & 658 & $1539(100)$ \\
\hline
\end{tabular}

Table 4.5. Pathology of infestations of the toes

\begin{tabular}{|l|l|l|l|l|l|l|}
\hline & \multicolumn{5}{|c|}{ Pathology } \\
\hline & $\begin{array}{c}\text { hypertrop } \\
\text { hic nail } \\
\text { rim }\end{array}$ & Fissure & Ulcer & $\begin{array}{c}\text { deformati } \\
\text { on of nails }\end{array}$ & $\begin{array}{c}\text { loss of } \\
\text { nail }\end{array}$ & $\begin{array}{c}\text { deformati } \\
\text { on of toe }\end{array}$ \\
\hline $\begin{array}{l}1^{\text {st }} \text { Left } \\
\text { toe }\end{array}$ & $7(3.6)$ & $25(12.7)$ & $16(8.1)$ & $33(16.8)$ & $93(47.2)$ & $28(14.2)$ \\
\hline $\begin{array}{l}1^{\text {st }} \text { Right } \\
\text { toe }\end{array}$ & $52(56.5)$ & $27(29.3)$ & $13(14.1)$ & $0(0.0)$ & $0(0.0)$ & $0(0.0)$ \\
\hline $\begin{array}{l}2^{\text {nd }} \text { Left } \\
\text { toe }\end{array}$ & $29(18.6)$ & $22(14.1)$ & $42(26.9)$ & $24(15.4)$ & $21(13.5)$ & $18(11.5)$ \\
\hline $\begin{array}{l}2^{\text {nd }} \text { Right } \\
\text { toe }\end{array}$ & $57(38.0)$ & $33(22.0)$ & $24(16.0)$ & $23(15.3)$ & $10(6.7)$ & $3(2.0)$ \\
\hline
\end{tabular}


Texila International Journal of Public Health Volume 4, Issue 4, Dec 2016

\begin{tabular}{|l|l|l|l|l|l|l|}
\hline $\begin{array}{l}3^{\text {rd }} \text { left } \\
\text { toe }\end{array}$ & $5(5.4)$ & $15(16.3)$ & $22(23.9)$ & $35(38.0)$ & $13(14.1)$ & $2(2.2)$ \\
\hline $\begin{array}{l}3^{\text {rd }} \text { Right } \\
\text { toe }\end{array}$ & $23(19.5)$ & $\begin{array}{l}41.0(34 . \\
7)\end{array}$ & $25(21.2)$ & $15(12.7)$ & $7(5.9)$ & $7(5.9)$ \\
\hline $\begin{array}{l}4^{\text {th }} \text { Left } \\
\text { toe }\end{array}$ & $15(8.6)$ & $13(7.5)$ & $18(10.3)$ & $39(22.4)$ & $45(25.9)$ & $44(25.3)$ \\
\hline $\begin{array}{l}4^{\text {th }} \text { Right } \\
\text { toe }\end{array}$ & $13(8.4)$ & $69(44.5)$ & $23(14.8)$ & $6(3.9)$ & $22(14.2)$ & $22(14.2)$ \\
\hline $\begin{array}{l}5^{\text {th }} \text { Left } \\
\text { toe }\end{array}$ & $36(19.9)$ & $30(16.6)$ & $33(18.2)$ & $57(31.5)$ & $25(13.8)$ & $0(0.0)$ \\
\hline $\begin{array}{l}5^{\text {th }} \text { Right } \\
\text { toe }\end{array}$ & $16(8.0)$ & $46(23.0)$ & $27(13.5)$ & $35(17.5)$ & $63(31.5)$ & $13(6.5)$ \\
\hline $\begin{array}{l}\text { Total } \\
\text { Patholog } \\
\text { y }\end{array}$ & $253(16.59)$ & $\begin{array}{l}323(21.1 \\
8)\end{array}$ & $\begin{array}{l}243(15.9 \\
3)\end{array}$ & $270(17.70)$ & $\begin{array}{l}299(19 . \\
60)\end{array}$ & $137(8.98)$ \\
\hline
\end{tabular}

Note: total pathological cases were 1525

Table 4.6. Severity and pathology of infestations of other body sites

\begin{tabular}{|l|l|l|l|l|l|}
\hline $\begin{array}{c}\text { Site of } \\
\text { infestation }\end{array}$ & \multicolumn{1}{|c|}{ Mild } & Moderate & \multicolumn{1}{|c|}{ Sever } & $\begin{array}{c}\text { Desquamation } \\
\text { of skin }\end{array}$ & $\begin{array}{c}\text { Ulcer of } \\
\text { the skin }\end{array}$ \\
\hline Sole & $14(24.56)$ & $27(47.36)$ & $16(28.08)$ & $41(71.92)$ & $16(28.08)$ \\
\hline Lateral rim & $11(20.37)$ & $10(18.52)$ & $33(61.11)$ & $17(31.49)$ & $37(68.51)$ \\
\hline Heel & $6(54.55)$ & $1(9.1)$ & $4(36.35)$ & $6(54.55)$ & $5(45.45)$ \\
\hline Right arm & $3(30)$ & $3(30)$ & $4(60)$ & $6(60)$ & $4(40)$ \\
\hline Left arm & $3(23.07)$ & $4(30.77)$ & $6(46.16)$ & $5(38.5)$ & $8(61.5)$ \\
\hline
\end{tabular}

\subsubsection{The age group of Musokoto residents mostly infested by tunga penetrans}

The study revealed that $52.5 \%$ of those with tungiasis were aged below 10 years. The remaining victims were aged above 10 years of age. Table 4.7 shows the details on the prevalence of tunga penetrans with age.

Table 4.7. Prevalence of tunga penetrans with age

\begin{tabular}{ll}
\hline Age range & Frequency $\mathbf{n ( \% )}$ \\
\hline $1-5$ & $86(19.5)$ \\
$6-10$ & $135(33.0)$ \\
$11-15$ & $64(14.5)$ \\
$16-20$ & $34(7.7)$ \\
$21-25$ & $20(4.5)$ \\
$26-30$ & $14(3.2)$ \\
$31-35$ & $14(3.2)$ \\
$36-40$ & $11(2.5)$ \\
$45-50$ & $17(3.9)$ \\
$>50$ & $35(8.0)$ \\
\hline
\end{tabular}

Establish the risk factors associated with tungiasis in Musokoto sub-location.

\section{Individual risk factors}

The individual risks factors that were investigated in this study were on where one sleeps, what is put on feet while inside the room, where time is spent, and participant's opinion on source of jiggers. A total 440 household heads/guardians responded to these questions. The study findings revealed that 389(88.4\%) slept on traditional made beds, 46(10.5\%) used 
Texila International Journal of Public Health

Volume 4, Issue 4, Dec 2016

mattresses on modern beds, 3(0.7\%) used mattresses laid on the floor whereas $2(0.5 \%)$ used mats laid on the floor. Out of the 440 household head/guardians 394(89.5\%) mentioned that they put on slippers while inside the rooms whereas 46(10.5\%) said they walk barefooted while inside the room. Majority of the household heads/guardians 388(88.2\%) said members of their families spent most of their times resting within their yards. Another 115(26.13\%) said they spent most their time inside the house. When asked about the sources of jiggers a sizeable number of the household/guardians, 364(82.7\%) did not have an idea where jiggers come from. About 43(9.8\%) were of the opinion that jiggers from sand, 19(4.3\%) and 14(3.2\%) said that jiggers come from pigs and dogs respectively. Other sources of jiggers that were also mention included dirt 22(5\%), dust $11(2.5 \%)$ whereas $3(0.68 \%)$ and $2(0.45 \%)$ respectively argued that jiggers were as a consequence of drought and climate change. When the association between jiggers infestation was computed using logistical regression analysis it emerged that where one sleeps i.e. mattress/bed, mattresses/floor, mat/floor and traditional beds was more likely to significantly influence jiggers infestation $(\mathrm{P}<0.001$; OR=1.319; $\mathrm{CI}=$ $1.180-1.474)$. Other individual risk factors such as what one put on feet while inside or outside the house and where time is spent were significantly less likely to influence jiggers infestation (what is put on inside the house $-\mathrm{P}<0.001$, $\mathrm{OR}=0.134$, $\mathrm{CI}=0.106-0.171$; what is put on feet outside the house $-\mathrm{P}<0.001$, $\mathrm{OR}=0.107$, $\mathrm{CI}=0.08-0.144$ and where time is spent $-\mathrm{P}<0.001, \mathrm{OR}=0.159, \mathrm{CI}=0.129-0.197$. See table 4.9.

Table 4.8. Individual risk factors and tungiasis in Musokoto.

\begin{tabular}{lll}
\hline Variable & Frequency n(\%) & P-Value \\
\hline Where one sleeps & & \\
Matress/bed & $46(10.5)$ & $<0.001$ \\
Matress/floor & $3(0.7)$ & \\
Mat/floor & $2(0.5)$ & \\
Traditional bed & $389(88.4)$ & \\
What is put on feet inside a room & \\
Slippers & $394(89.5)$ & $<0.001$ \\
Barefoot & $46(10.5)$ & \\
Resting place & & \\
Veranda & $7(1.6)$ & $<0.001$ \\
Yard & $388(88.2)$ & \\
Backyard & $45(10.2)$ & \\
Where else time is spent & \\
House & $115(26.13)$ & $\mathbf{0 . 0 1 5}$ \\
Under a tree & $30(6.81)$ & \\
Source of jiggers & & \\
Pig & $19(4.3)$ & $<0.001$ \\
Sand & $43(9.8)$ & \\
Dog & $14(3.2)$ & \\
Don't know & $364(82.7)$ & \\
Other sources of jiggers & \\
Dirt & $22(5)$ & \\
Dust & $11(2.5)$ & \\
Drought & $3(0.68)$ & \\
Climate change & $2(0.45)$ & \\
Don't know & $402(91.37)$ & \\
\hline
\end{tabular}


Table 4.9. Association between jiggers infestation and individual risk factors

\begin{tabular}{|l|l|l|l|l|l|}
\hline Variable & df & $\mathbf{P =}$ value & OR & \multicolumn{2}{|l|}{$\mathbf{9 5 . 0 \%}$ C.I. } \\
\hline & & & & Lower & Upper \\
\hline Where one sleeps & 1 & $<0.001$ & 1.319 & 1.180 & 1.474 \\
\hline $\begin{array}{l}\text { What is put on feet inside the } \\
\text { house }\end{array}$ & 1 & $<0.001$ & 0.134 & 0.106 & 0.171 \\
\hline $\begin{array}{l}\text { What is put on feet outside } \\
\text { the house }\end{array}$ & 1 & $<0.001$ & 0.107 & 0.080 & 0.144 \\
\hline Where time is spent resting & 1 & $<0.001$ & 0.159 & 0.129 & 0.197 \\
\hline
\end{tabular}

\section{Accommodation risk factors associated with tungiasis}

The study revealed that all the households $440(100 \%)$ were mud walled structures with only $3(0.7 \%)$ of concrete/cement house floor and $437(99.3 \%)$ of the households were of sand/mud floor. However 417(94.8\%) of the houses had zinc/iron roofing whereas only 23(5.2\%) being grass thatched. The other aspects of accommodation that were also investigated in relation to jiggers infestation were type of street and type of lighting system used by a household. It emerged that 423(96.1\%) of the households were situated along sand/murram roads or paths whereas $17(3.9 \%)$ of the households were in areas where the street was of clay type of soil. When asked about the lighting system 439(99.8\%), which is almost $100 \%$ of the participants said they used kerosene or lamp to light their houses. Table 4.10.

Table 4.10. Family and individual risk factors and tungiasis in Musokoto.

\begin{tabular}{|c|c|c|}
\hline Variable & Frequency n(\%) & P-Value \\
\hline \multicolumn{3}{|l|}{ House structure } \\
\hline Concrete & $0(0)$ & 0.003 \\
\hline Mud & $440(100)$ & \\
\hline \multicolumn{3}{|l|}{ House floor } \\
\hline Concrete/cement & $3(0.7)$ & 0.024 \\
\hline Sand/mud & 437(99.3) & \\
\hline \multicolumn{3}{|l|}{ House roof } \\
\hline Zink/iron & $417(94.8)$ & 0.065 \\
\hline Grass thatched & $23(5.2)$ & \\
\hline \multicolumn{3}{|l|}{ Type of street } \\
\hline Sand/murram & 423(96.1) & 0.766 \\
\hline Clay & 17(3.9) & \\
\hline \multicolumn{3}{|l|}{ House light } \\
\hline Electricity & $0(0)$ & 0.393 \\
\hline Kerosene/lamp & 439(99.8) & \\
\hline Solar & $1(0.2)$ & \\
\hline
\end{tabular}

Logistical regression analysis was performed to establish the association between jigger's infestations and accommodation risk factors highlighted above. The analysis revealed house floor types was significantly associated with tungiasis and that house hold floor types was three times more likely to influence jigger's infestation. $(\mathrm{P}=0.036$, OR $=3.608, \mathrm{CI}=1.089-$ 11.955). The type of street or soil type was less likely to influence jiggers infestation ( $\mathrm{P}=$ 0.789 , $\mathrm{OR}=1.802$, $\mathrm{CI}=0.607-1.930$ ). See details in table 4.11 . 
Texila International Journal of Public Health

Volume 4, Issue 4, Dec 2016

Table 4.11. Association between jigger's infestation and family and individual risk factors

\begin{tabular}{|l|l|l|l|l|l|}
\hline Variable & df & P= value & OR & \multicolumn{2}{|l|}{$\mathbf{9 5 . 0 \%}$ C.I. } \\
\hline & & & & Lower & Upper \\
\hline House floor type & 1 & 0.036 & 3.608 & 1.089 & 11.955 \\
\hline House roof & 1 & 0.054 & 0.629 & 0.393 & 1.009 \\
\hline Street & 1 & 0.789 & 1.082 & 0.607 & 1.930 \\
\hline House light & 1 & 0.927 & 0.937 & 0.235 & 3.745 \\
\hline
\end{tabular}

\section{Water and sanitation risk factors}

Water and sanitation risk factors associated with tungiasis infestation were also investigated. The water risk factors looked at the sources of water whereas the sanitation risk factors that were investigated included where waste sources are put; and treatment given to the waste products as well as the site of the waste bin. Approximately 413(93.9\%) of the household sourced there water from the river whereas 27(6.1\%) sourced their water from the wells. Other water sources were boreholes $1(0.2 \%)$ and spring 20(4.5\%). On sanitation 396(90.0\%) disposed-off their waste in the household garden and 26(5.9\%) disposed in the yard and 18(4.1\%) disposed-off their waste in the compost pit. When asked whether they burned their waste or not, only 18(4.1\%) answered in the affirmative whereas 422(95.9\%) did not burn their waste. All the $440(100 \%)$ of the household did not have a waste bin within the house compound.

Logistical regression analysis (table 4.12) confirmed that source of water, household waste disposal and treatment significantly influenced jiggers infestation $(\mathrm{P}=0.001, \mathrm{OR}=2.050$, CI $=1.334-3.150$ ) for source of water implying that source of water was more likely to influence jiggers infestation compared to waste disposal site $(\mathrm{P}<0.001, \mathrm{OR}=0.564, \mathrm{CI}=$ $0.409-0.776)$ and waste treatment e.g. burning $(\mathrm{P}=0.002$, $\mathrm{OR}=0.449, \mathrm{CI}=0.268-0.751)$. See details in table 4.13

Table 4.12. Water and sanitation risk factors associated with tungiasis in Musokoto.

\begin{tabular}{|c|c|c|}
\hline Variable & Frequency n(\%) & P-Value \\
\hline \multicolumn{3}{|c|}{ Source of water supply } \\
\hline Well & $27(6.1)$ & 0.001 \\
\hline River & 413(93.9) & \\
\hline \multicolumn{3}{|c|}{ Other water sources } \\
\hline Borehole & $1(0.2)$ & $<0.001$ \\
\hline Spring & $20(4.5)$ & \\
\hline \multicolumn{3}{|c|}{ Waste product (place to put) } \\
\hline Yard & $26(5.9)$ & 0.001 \\
\hline Garden & $396(90.0)$ & \\
\hline Compost pit & $18(4.1)$ & \\
\hline \multicolumn{3}{|c|}{ Burn the waste? } \\
\hline Yes & $18(4.1)$ & 0.002 \\
\hline No & $422(95.9)$ & \\
\hline \multicolumn{3}{|c|}{ Waste bin in the home? } \\
\hline Yes & $0(0)$ & 0.001 \\
\hline No & $440(100)$ & \\
\hline
\end{tabular}


Table 4.13. Association between jigger's infestation and water and sanitation risk factors

\begin{tabular}{|l|l|l|l|l|l|}
\hline Variable & df & P= value & OR & \multicolumn{2}{|l|}{$\mathbf{9 5 . 0 \%}$ C.I. } \\
\hline & & & & Lower & Upper \\
\hline Source of water & 1 & 0.001 & 2.050 & 1.334 & 3.150 \\
\hline Where is household waste put & 1 & $<0.001$ & 0.564 & 0.409 & 0.776 \\
\hline Burn the waste & 1 & 0.002 & 0.449 & 0.268 & 0.751 \\
\hline
\end{tabular}

\section{Type of domesticated animal and risk factors associated with tungiasis.}

Of the 440 households only 19(4.3\%) of the households domesticated dogs and 421(5.7\%) did not have dogs. A total of $9(42.90 \%)$ had at least one dog whereas $1(4.80 \%)$ had four and five dogs each. When asked about domestication of cats only 15(3.4\%) confirmed that they domesticated cats of this 14(45\%) had at least one cat and only 1(5\%) had up to four cats. Pigs were domesticated by $12(3.4 \%)$ of the households. Of the twelve households that domesticated pigs $7(58.33 \%)$ had a pigsty whereas $5(41.67 \%)$ practiced free range pig keeping. The participants also mentioned domestication of other animals e.g. goats $2(0.5 \%)$, chicken 18(4.1\%) and cows 27(6.1\%). See table 4.14.

Logistical regression analysis revealed that having a dog or cat and numbers of such dogs or cats significantly influenced jiggers infestation and the number of dogs present was more likely to significantly influence $(\mathrm{P}=0.001$, $\mathrm{OR}=1.179$, $\mathrm{CI}=1.070-1.299)$ jiggers infestation compared to the number of cats $(\mathrm{P}=0.006$, OR $=1.145$, $\mathrm{CI}=1.040-1.261)$. Having other animals was more likely to significantly influence $(\mathrm{P}<0.001, \mathrm{OR}=1.517, \mathrm{CI}=$ $1.234-1.864)$ jiggers infestation. The presence of rats in the house was less likely to influence $(\mathrm{P}<0.001, \mathrm{OR}=0.477, \mathrm{CI}=0.334-0.680)$. See table 4.15 .

Table 4.14. Risk factors of type of animal domesticated and tungiasis in Musokoto

\begin{tabular}{|c|c|c|}
\hline Variable & Frequency n(\%) & P-Value \\
\hline \multicolumn{3}{|c|}{ Domesticate a dog? } \\
\hline Yes & $19(4.3)$ & 0.001 \\
\hline No & $421(95.7)$ & \\
\hline \multicolumn{3}{|c|}{ How many dogs? } \\
\hline 1 & $9(42.90)$ & 0.013 \\
\hline 2 & $6(28.60)$ & \\
\hline 3 & $4(19.00)$ & \\
\hline 4 & $1(4.80)$ & \\
\hline 5 & $1(4.80)$ & \\
\hline 6 & $0(0)$ & \\
\hline \multicolumn{3}{|c|}{ Do you have a cat? } \\
\hline Yes & $15(3.4)$ & 0.005 \\
\hline No & $(96.6)$ & \\
\hline \multicolumn{3}{|c|}{ How many cats? } \\
\hline 1 & $14(45)$ & 0.037 \\
\hline 2 & $1(30)$ & \\
\hline 3 & $4(20)$ & \\
\hline 4 & $1(5)$ & \\
\hline \multicolumn{3}{|c|}{ Domesticate a pig? } \\
\hline Yes & $12(3.4)$ & 0.360 \\
\hline No & 428(97.3) & \\
\hline \multicolumn{3}{|c|}{ If YES how do they live? } \\
\hline Pigsty & $7(58.33)$ & 0.271 \\
\hline Free & $5(41.67)$ & \\
\hline
\end{tabular}


Texila International Journal of Public Health

Volume 4, Issue 4, Dec 2016

Table 4.14. Risk factors of type of animal domesticated and tungiasis in Musokoto

\begin{tabular}{ccc}
\hline Variable & Frequency n(\%) & P-Value \\
\hline \multicolumn{3}{c}{ Other animals domesticate? } \\
Yes & 47(10.7) & $<0.001$ \\
No & 393(89.3) & \\
What type of animals? & $<0.001$ \\
Goat & 2(0.5) & \\
Cow & 27(6.1) & \\
Chicken & 18(4.1) \\
N/A & 393(89.3) & \\
\hline
\end{tabular}

Table 4.13. Association between jigger's infestation and Risk factors of type of animal domesticated.

\begin{tabular}{|l|l|l|l|l|l|}
\hline Variable & df & P= value & OR & \multicolumn{2}{|l|}{$95.0 \%$ C.I. } \\
\hline & & & & Lower & Upper \\
\hline Have a dog & 1 & 0.001 & 0.422 & 0.256 & 0.696 \\
\hline No. of dogs & 1 & 0.001 & 1.179 & 1.070 & 1.299 \\
\hline Have a cat & 1 & 0.006 & 0.541 & 0.257 & 0.792 \\
\hline No. of cats & 1 & 0.006 & 1.145 & 1.040 & 1.261 \\
\hline Have a pig & 1 & 0.282 & 0.700 & 0.366 & 1.341 \\
\hline No. of pigs & 1 & 0.160 & 1.090 & 0.967 & 1.228 \\
\hline Where the animals live & 1 & 0.538 & 1.140 & 0.750 & 1.733 \\
\hline Have other animals & 1 & $<0.001$ & 1.517 & 1.234 & 1.864 \\
\hline Rats present in the house? & 1 & $<0.001$ & 0.477 & 0.334 & 0.680 \\
\hline
\end{tabular}

To establish the modes of treatment used by the residents to manage the disease.

When participants were asked if they removed jiggers, 440(100\%) said they do using needles 247(56.1\%) and sticks/thorns 193(43.9\%). To treat the jiggers, kerosene 402(91.4\%) was mostly used while $38(8.6 \%)$ used no products in the market. No participant used savlon antiseptic. Other products mentioned to be used include hydrogen peroxide $1(0.22 \%)$, cattle dip 2(0.45\%), Omo 5(1.13\%), magadi (sodium bicarbonate) $3(0.68 \%)$ and warm water 2(0.45\%). See table 4.14 .

Table 4.14. Modes of treatment used by the residents of Nambale to manage tungiasis.

\begin{tabular}{|c|c|c|}
\hline Variable & Frequency n(\%) & P-Value \\
\hline \multicolumn{3}{|c|}{ What do you do in case of a jigger infestation? } \\
\hline Remove the jigger & $440(100)$ & $<0.001$ \\
\hline \multicolumn{3}{|c|}{ How do you remove the jiggers? } \\
\hline Needle & 247(56.1) & $<0.001$ \\
\hline Stick/thorn & 193(43.9) & \\
\hline \multicolumn{3}{|c|}{ Products used in treating jigger wounds } \\
\hline No product used & $38(8.6)$ & $<0.001$ \\
\hline Kerosene & 402(91.4) & \\
\hline Savlon & $0(0)$ & \\
\hline \multicolumn{3}{|c|}{ Other products used in treating jigger wounds } \\
\hline Hydrogen peroxide & $1(0.22)$ & 0.216 \\
\hline Cattle dip & $2(0.45)$ & \\
\hline Magadi & $5(1.13)$ & \\
\hline Omo & $3(0.68)$ & \\
\hline Warm water & $2(0.45)$ & \\
\hline
\end{tabular}




\section{Discussion}

The study findings are discussed objective wise while cross - reference with similar studies done elsewhere. The first specific objective was to establish the prevalence of tungiasis among residents of Musokoto sub-location. The study findings point that out of the study participants (1557), only a third said they had had jiggers at one time in their lives and on clinical examination of those who answered in the affirmative sixty five percent were found to be slightly higher compared to a similar study done by Ade-Serrano and Ejezie (1981) in a rural Lagos State, Nigeria. In the Lagos study the prevalence of tungiasis was forty percent. In another study done in two towns of South - West Trinidad revealed a tungiasis prevalence of thirty one and forty percent, respectively for the two towns i.e. Icacos and Fullarton (Chadee et al., 1991a, 1991b). In another study Ade-Serrano and Ejezie (1982) found a prevalence of 42 percent in a Southern town of Nigeria.

The prevalence of jiggers in males and females was almost equal implying that gender did not significantly influence the prevalence of jiggers $(p=0.743)$. Looked at by age it emerged that age of an individual significantly influenced the prevalence of jiggers. This finding corroborates that of Heukelbach (unpublished observation) that equally revealed that jiggers was more prevalent in children than in adults. Looking at prevalence by specific age groups, the observation in the current study is similar to that of Heukelbach et al. (unpublished observation).

Arene (1984) and Chadee (1994) argues that decline in tungiasis by increase in an individual's age could be a function of keratinization. Nevertheless, this could be due to a number of socio-economic and personal factors such as evidenced in the current study. Previous studies have linked tungiasis infestation to families of poor socio-economic status. The study participants in the current study were living in the rural areas of Musokoto and were of very poor socio-economic status (table 4.2). Additionally, Heukelbach, (2005) and Litvoc et al., (1991) equally linked poor socio-economic status to high prevalence of tungiasis. The other aspect of prevalence that was investigated was body sites infested and severity of the infestation. The current study has demonstrated that jiggers can infest any part of the body i.e. toes, sole, lateral rim of sole; heel and arms. Jiggers infestation presented in the form of fissures; hyperthropic nail rim; ulcerations; nail and toe deformation and loss of nails. Others included desquamation and ulceration of the skin. Feldmeier et al., 2003; Feldmeier and Heukelbach, 2009 in separate reports on epidermal parasitic skin diseases sheds light on pathology and severity of tungiasis on finger nails and heels, toes confirming similar jiggers manifestation by tungiasis as was observed in the current study.

Ferran et al. (2009) also realized that a nodular lesion on the sole of a patient who had visited Venezuella contained Tunga penetrans flea. Nordlund, (2009) was also able to diagnose tungiasis from the hands, skin, toes, nails and sole of his patients. Also according to Nordlund (2009) the cases presented in the form of fissures, abscesses, suppurations. The lesions, according to Nordlund (2009) can progress into osteomyelitis or gangrenes and nails can be lost in most cases.

The second specific objective of the study explored the risk factors associated with tungiasis.

Pilger et al. (2008) argues that tungiasis is much more prevalent in communities who usually wear flip - flop (slippers) and often sleep on dirty floors. The challenges with the term dirty floor that Pilger and colleagues, (2008) did not clarify the meaning of dirty floors. But assuming that' dirty floors' is synonymous to mud floors then the findings of the current study is in agreement with the views of Pilger and his colleagues (2008). Mazigo et al., (2010) while conducting a tungiasis prevalence survey in a rural village in Ruseas ward of Tanzania describes the housing condition of the infested as one with mud walls made of tree poles and a dusty dirty floor littered with garbage. This clearly confirms that tungiasis is associated with dirty living environments. In this view, therefore it is critical that residents of Musokoto improve on their housing conditions especially materials used in flooring. Unregulated disposal of household waste can lead to animals such as rodents residing within 
the homestead and this can lead to difficulty in controlling the jigger flea, which can reside and feed even on rats (Witts et al., 2004). Cleanliness and tidiness of the household and its environments is very important not only in controlling Tunga penetrans but also other household bugs (Curtis et al., 2003). In this study, it is in agreement with Witts and colleagues above information since Musokoto residents with unregulated disposal of waste associated with tungiasis infestation on table 4.12.

Reportedly, Pampiglione et al. (2003; 2009) revealed that sand flea (Tunga spp.) infestations in humans and domestic animals were positively correlated i.e. domestication of animals was linked to Tunga penetrans infestation in humans. The animals that Pampiglione linked to Tunga penetrans infestation in humans were dogs and pigs. The domestic animals previously associated with Tunga penetrans (Pampiglione et al., 2003; 2009) and were also mentioned in the current study included goats, cats, pigs, bovines and chickens. Other studies (Ribeiro et al., 2007; Heukelbach, 2004; Linardi and Guimaraes, 2000; Fioravanti et al., 2003; Pampiglione et al. 2003; 2009) have also reported and linked domestic animals as hosts to Tunga penetrans flea, which the causative agent of tungiasis.

The third specific objective investigated treatment modes used by residents of Musokoto to treat tungiasis. In many cases tungiasis is a self-limiting infestation upon removal of the Tunga penetrans ball. However, due to the resulting skin rupture, infections may result, especially in cases of poor personal hygiene and environmental sanitation. It is therefore imperative that tungiasis is treated. In the current study, the study participants indicated use of various modes of treatment including physical removal of the jigger. Products mentioned to be used to treat jigger infestation/infections after removal of the jigger ball are kerosene, savlon, hydrogen peroxide, cattle dip, sodium bicarbonate (soda ash), omo and use of warm water.

Nordlund (2009) recommends that jiggers should be removed surgically under sterile conditions. Heukelbach (2006) has advised that there are no effective oral or topical drugs that can be used in the treatment of tungiasis. Nevertheless, in a study using a plant-based repellant - Zanzarin, a lotion made from coconut oil; jojoba oil and aloe vera, applied twice daily reduced newly imbedded fleas by $92 \%$ and the number of skin lesions by $87 \%$. The limitation of the current study was that it did not capture the success through follow up of the modes of treatment used by Musokoto residents infested with jiggers on their reduction of imbedded jigger fleas and also in the reduction of skin lesions. Worth noting is the high prevalence of tungiasis among the study participants, which in itself is a pointer that the modes of treatments used by the study participants are not effective and so a more effective anti-tunga ointment such as Zanzarin could be recommended for topical use by Musokoto residents. This recommendation is supported by the documented success of Zanzarin by the previous studies (Feldmeier et al., 2006; Schwalferberg et al., 2004). In the Tanzania study Mazigo et al. (2010) advised the caretakers of the jiggers infested individuals to clean the wounds of the victims using Dettol and also to take the infested persons for tetanus vaccination. In the current study it was not known whether persons infested with jiggers were actually vaccinated against tetanus. Lack of tetanus vaccination of those infested with jiggers may be a health threat to such persons, especially young children who play with soil and so may be exposed to infections by Clostridium tetanii.

\section{Conclusion}

\section{Prevalence}

There was a high prevalence of tungiasis in the division and most of the cases were found in children of schooling age. This is attributed to barefoot walking to school and domesticating animals in the homestead.

\section{Risks factors}

As evident from the study, where one sleeps and spends time while at home determines human infestation of jiggers. If persons spend most time resting outside the house and sleeps 
on the floor they will get infested with jiggers. Mud floor types and sand streets is also the habitat for jiggers. Pigs, dogs and cats also harbor jiggers and the more they are in the compound and living with humans, the more the chances of getting tungiasis among the family members. People fetching water from long distances i.e. rivers have higher chances of infestation.

\section{Modes of treatment}

Most residents used crude methods for surgical removal of the jigger and also used none recommended products for its treatment. These products could cause infection and other complications such as tetanus and gangrene among others.

\section{Recommendations}

1. More emphasis/strategies to be put in the control and management of tungiasis at musokoto Location because of the high prevalence in the area.

2. Health education regarding tungiasis to be provided to the community on its management, stigma, and control. School children to wear shoes while they go to school to avoid infestation.

3. Regular domesticated animals spraying with insecticides will help reduce the fleas in the animals hence reduced egg larvae.

4. It emerged that victims of jiggers infestations do not receive tetanus vaccination, it is herby recommended that the government should consider vaccinating residents of jigger endemic areas with tetanus vaccines.

\section{References}

[1]. Ade-serano A, Olomolehin G, and Adewenwi G. (1982): Treatment of human tungiasis with niridazole: a double blind placebo controlled trial. Annals of Tropical Medicine and Parasitology, 76, 89-92.

[2]. Ahadi Trust. (2010). The jigger menace in Kenya: Jigger magazine, 2(1). retrieved 26 June 2012, www.ahadi-trust.org.

[3]. Arene Fo. (1984) The prevalence of sand flea (Tunga penetrans) among primary and post-primary school pupils in Choba area of the Niger Delta. Public Health; 98: 282 - 283.

[4]. BDSP. (2010): Implementation of the national population policy for sustainable development. Ministry of planning and national development. Nairobi: HSK consulting LTD.

[5]. Choge J, Wanjala P, Koech J, Kirui S, and Ayaya S. (2006): Tunga penetrans, pediculus capitis and sacorpte scabei among children $<15$ yrs in Kamgut location, Uasin Gishu district, Kenya. Journal of Agriculture Moi university, 5: 38-44.

[6]. Collin G, McLeod T, Konfor N, Lamnyan C, and Ngarka L. (2009): Tungiasis. A neglected health problem in rural Cameroon. International Journal of Collaborative Research on Internal Medicine and Public Health, 1(A): 2-10.

[7]. Feldmeier H, Eisele M, Van Marck, Mehlhorn H, Ribeiro R, and Heukelbach Jorg. (2004): Investigation on the biology, epidemiology, pathology and control of Tunga penetrans in Brazil: Clinical and Histopathology. Parasitology Research, 94: 275 e82.

[8]. Feldmeier H, Heukelbach J, Eisele M, Souza A, \& Barbosa L. (2002): Bacterial superinfection in human tungiasis. Journal of Tropical Medicine and International Health, 7: 559-64.

[9]. Groove S, \& Burns Nancy. (2003): Understanding Nursing Research: Building evidence based practice (4th ed.). St Louis Missouri: Saunders Elsevier.

[10]. Heemskerk J, Van Empel, \& Jakimowicz J. (2005): Tunga penetrans: A case report and review of literature. Acta Chirulgica Belgica, 105: 548-550.

[11]. Heukelbach J. (2004). The animal reservoir of Tunga penetrans in severely affected communities of North east Brazil. Medical Veterinary Entomology, 18(5); 329-33.

[12]. Heukelbach J, Franck S, and Feldmeier H. (2004): Therapy of tungiasis: a double randomized control trial with oral ivermectin. Memorias Do Instituto Oswaldo Cruz, 99; 873-6. 
Texila International Journal of Public Health

Volume 4, Issue 4, Dec 2016

[13]. Heukelbach J, Wilcke T, Eisele M, \& Feldmeier H. (2002): Ectopic localization of tungiasis. Journal of Tropical Medicine and Hygiene, 67; 214-216.

[14]. Heukelbach J, Wilcke T, Harms G, and Feldmeier H. (2005): Seasonal variation of tungiasis in an endemic community. American Journal of Tropical Medicine and Hygiene, 72; 145-149.

[15]. Heukelbach, J., Costa, A., Wilcke, T., Mencke, N., and Feldmeier, H. (2004). The animal resorvour of Tunga Penetrans in severely affected communities of Nothern Brazil. Medical and Vetenary Entomology, 18; 329 - 335.

[16]. Hoeppli R. (1963): Early references to the occurence of Tunga penetrans on Tropical Africa. Acta Tropica, 20; 143-52.

[17]. Joseph J, Bazile J, Mutter J, Shin S, Ruddle A, Ivers L, and Lyon E. (2006): Tungiasis in rural Haiti: a community based response. Transaction of Royal Society of Tropical Medicine and Hygiene, 100; 970-974.

[18]. Linardi, J., and Guimaraes, L. (2000). Sifona Pterosdo Brazil. Museu Zoologico Universidade Sao Paolo, 48 - 53.

[19]. Litvoc, J., Leite, R., and Katz, G. (1991). Apsectos epidemiolo Agicos do te Atano no estado de Sao Paulo Brazil. Revista Do Instituto de Medicina Tropical De Sao Paulo, 477 - 484.

[20]. Mazigo H, Behamana E, and Zinga M. (2010): Tungiasis infestation in Tanzania: A case report. Journal of Infection in Developed Countries, 4(3); 187-189.

[21]. Molyneux D, Hotez P, and Fenwick A. (2005): Rapid-impact interventions: How policy of intergrated control for Africa's neglected tropical diseases could benefit the poor. Public Library of Science, Medicine, 2; 298 e87.

[22]. Muehlen M, Feldmeier H, Wilcke T, and Heukelbach J. (2006): Identifying risk factors for tungiasis and heavy infestation in a resource-poor community in Northeast Brazil. Transaction of Royal Society of Tropical Medicine and Hygiene, 100; 371-380.

[23]. Nordlund, J.J. 2009. Cutaneous ectoparasites. Dermatologic Therapy; 22: 503-517

[24]. Njau N, Wanzala P, Marion M, Liana A, \& Heukelbach J. (2012): Tungiasis in rural Kenya, an emerging infectious disease. Retrovirology, 9; 1-37.

[25]. Njeumi F, Nsangou C, Ndjend A, Koga G, Ostanello F, and Pampiglione S. (2002): Tunga penetrans in Cameroun. Revue de Medecine Veterinaire, 153: 176-180.

[26]. Pampiglione S, Fioravanti M, Gustinelli A, and Onore G. (2009): Sand flea (Tunga spp.) infections in humans and domestic animals: state of art. Medical Veterinary Entomology, 2:172.

[27]. Pampiglione, S., Fioravanti, M., Gustinelli, G., Onore, B., Mantovani, A., and Luchetti, C. (2009). Sand flea (Tunga ssp) infections in humans and domestic animals: State of art. Medicine and Vetinary entomology, 23: 172 - 186.

[28]. Pampiglione, S., Tretini, M., Fioravanti, M., Onore, G., and Rivasi, F. (2003). Additional description of a new species of Tunga from Ecuador. Annal tropical Medicine of Parasitology, 10: 9 15.

[29]. Pilger, D., Schwalfenberg, S., and Heukelback, J. (2008). Investigations on the biology, epidemiology, pathology, and control of Tunga penetrans in Brazil: Importance of animal reservoirs for human infestation. Journal of parasitology, 102: 875 - 880.

[30]. Ribiero, J., Coehlo, S., and Ruas, J. (2007). Infestac de Tunga penetrans siphonaptera: Tungidae em cascos de vacas leteiras Holandez-Zebu. Arquivos Brazileiros De Medicina Veterinaria e Zootenicia, 59: 520 - 522.

[31]. Sanusi I, Brown E, Shepard T, \& Grafton W. (1989): Tungiasis: Report of one case and review of the 14 reported cases in the United States. Journal of the American Academy of Dermatology, 20(2): 941-4.

[32]. Schwalfenberg S, Witt LH, Kehr JD, Feldmeier H, Heukelbach J. 2004. Prevention of tungiasis using a biological repellent: a small case series. Ann Trop Med Parasitol; 98(1): 89-94.

[33]. Ugbomoiko U. (2007): Tungiasis: High prevalence, parasite load, and morbidity in a rural community in Lagos State, Nigeria. International Journal of Dermatology, 46: 475-481.

[34]. Ugbomoiko U, Ariza L, Ofoezie I, and Heukelbach J. (2007): Risk factors for Tungiasis in Nigeria: Identification of targets for effective intervention. Public Library of Science, Neglected Tropical Diseases, 1(3): e87. 
[35]. Wachira Ann. (2012): Tungiasis: Infestation of the jigger flea in resource poor communities in Africa. Africa Public Health, 1: 2.

[36]. WHO. (2010): Epidermal parasitic skin diseases: A neglected category of poverty associated plagues. Journal of the World Health Organization, 87: 152-159.

[37]. Winter B, Oliveira F, Wilcke T, Heukelbach Jorg, and Feldmeier H. (2009): Tungiasis-related knowledge and treatment practices in two endemic communities in Northeast Brazil. Journal of Infection in Developed Countries, 3(6): 458-66.

[38]. Yamane T. (1967): Statistics: An introductory Analysis (2nd ed.). New York: Harper and Row. 